[Bull. Agr. Chem. Soc. Japan, Vol. 24, No. 1, p. 84 92, 1960]

\title{
Effect of Gamma-ray upon Food Microorganisms
}

\section{Part V. Studies on Survival of E. coli irradiated with Gamma-ray}

\author{
By Wataru Watanabe \\ Defartment of Agricultural Chemisiry, Tokyo University of Education, \\ and Niko Institule of Food, Niko Co., Lid.
}

Received May 11, 1959

\begin{abstract}
The author has carried out a series of studies on the effects of various environmental conditions on the survival of $E$. coli irradiated with gamma-ray. This report deals with the minimum gamma-ray dose-rate necessary for regular survival of the strain under a weak gamma-ray field in three kinds of media, influences of the vacuum procedure, and also, the effects of some other conditions.
\end{abstract}

\section{INTRODUCTION}

In the author's preceeding four reports ${ }^{1-4}$, a simplified method for the sterilization of $E$. coli by gamma-ray irradiation has been presented and also, the influences of various conditions prior to, during, and after irradiation on the survival of the strain irradiated with gammaray have been reported. However, in regard of each experiment many questions still remain unsolved. In the present investigations, the author has carried out several supplementary studies concerning the effects previously reported, of which the results are presented here.

\section{EXPERIMENTAL}

The strain used in this experiment was Escherichia coli strain $Y C 1$, one of the stock cultures of the School of Medicine, Keio University. The radiation source used Cobalt-60, of 40 Curies, preserved at the School of Medicine, Keio University. The duration of irradiation was 2 hours in most experiments, being occasionally adjusted to the range of from 14 minutes to 9 hours.

The samples were prepared as follows. Bacteria were centrifuged and washed two or three times with saline, suspended in saline at the concentration of $10^{3} \mathrm{cells} / \mathrm{ml}$,

1) W. Watanabe, Effect of Gamma-ray upon Food Micoorganisms (1), This Bulletin. 22, 68-77 (1958).

2) W. Watanabe, // (II), This Bulletin, 22, 255-261 (1958).

3) W. Watanabe, " (III), This Bulletin, 23, 73-77 (1958).

4) W. Waranabe, $"$ (IV), This Bulletin, 24, 75-83 (1960). and the suspension was diluted $(1: 10)$ with melted agar medium held at $40^{\circ} \sim 45^{\circ} \mathrm{C}$. One $\mathrm{ml}$ of the mixture was pipetted into a small petri-dish and solidified at room temperature. Therefore, these samples contained bacteria at the concentration of $10^{2}$ cells/samples $\mathrm{ml}$ in the agar medium.

All samples were irradiated at room temperature within the range of $19^{\circ}$ to $21^{\circ} \mathrm{C}$. The non-irradiated control samples were treated in the same way except in the irradiation procedure. After irradiation, all samples both irradiated and non-irradiated, were immediately placed into an incubator and incubated for 48 hours at $37^{\circ} \mathrm{C}$. When a pure agar medium was used for plating, both of the irradiated and non-irradiated control samples were covered with a nutrient agar medium prior to incubation. The colonies developed were scored with a binocular microscope.

The media used were nutrient agar, the minimum medium reported in Report III, and in Experiment 1 a pure agar medium, in Experiment 2 both nutrient agar and a pure agar medium, in Experiments 3, 4 and 5 only a nutrient agar medium, and in Experiment 6 a minimum agar medium. The procedures and results are described in detail in each section below.

\section{RESULTS AND DISCUSSION}

(1) Experiment 1: In Report III, the author has reported on the relation between the survival-ratio of $E$. coli and dose-rate of cobalt- 60 gamma-ray, and has mentioned that the survival-ratio of the strain in nutrient agar medium 
is directly proportional to the total irradiated dose in case of irradiation at a dose-rate exceeding $4,000 \mathrm{rep} / \mathrm{hr}$.

In the present experiment, three kinds of media, a minimum medium (synthetic medium), a pure agar medium (non-nutrient) and a nutrient agar medium containing $10 \%$ horse-serum were employed.

At first, twenty petri-dishes containing small numbers of bacteria and a minimum medium were irradiated for varied durations in which almost equivalent total doses of irradiation were administrated to the samples, i. e., 5,000 rep. The relation between the gamma-ray dose-rate and the duration of irradiation is presented in Table I, and the results of the table are also diagrammed in Figure 1. As shown in the figure, the survival-ratios resulted in almost an equivalent value of $48 \%$, in case of gamma-ray irradiation upon $E$. coli which was carried out in a minimum medium at a dose-rate of more than $2,000 \mathrm{rep} / \mathrm{hr}$. However, in case of irradiation at a dose-rate lower than $2,000 \mathrm{rep} / \mathrm{hr}$, the lower dose-rate of gamma-ray resulted in survival of more bacteria.

Following this procedure samples containing pure agar were irradiated for varied durations in which the total irradiation doses upon the samples showed almost the same values, i.e., 3,000 rep and 5,000 rep. The durations of irradiation were adjusted in the range of 14 minutes
TARLE I. DOSE-RATES AND DURATIONS OF IRRAD. OF SAMPLES AT THE DOSE OF 5,000 rep IN CASE OF USING A SYNTHETIC MEDIUM.

Sample Distance
No. from $\mathrm{Co}^{60}$ Dose-rate Irrad. time Survival S-ratio No. from $\mathrm{Co}^{60}$ Dose-rate

- $\quad-0 \mathrm{rep} / \mathrm{hr} \quad 0 \mathrm{hr} \quad 536 \quad 100 \%$

$\begin{array}{llllll}1 & 5.5 \mathrm{~cm} & 12758 & 0 \mathrm{~h}-24 \mathrm{~m} & 263 & 49.0\end{array}$

$\begin{array}{llllll}2 & 6.3 & 9723 & 0-31 & 259 & 48.3\end{array}$

$\begin{array}{llllll}3 & 7.1 & 7656 & 0-40 & 255 & 47.6\end{array}$

$\begin{array}{llllll}4 & 7.9 & 6210 & 0-48 & 264 & 49.2\end{array}$

$\begin{array}{llllll}5 & 8.7 & 5098 & 0-59 & 251 & 46.8\end{array}$

$\begin{array}{llllll}6 & 9.5 & 4277 & 1-10 & 260 & 48.5\end{array}$

$\begin{array}{llllll}7 & 10.3 & 3638 & 1-22 & 251 & 46.8\end{array}$

$\begin{array}{llllll}8 & 11.2 & 3077 & 1-38 & 252 & 47.0\end{array}$

$\begin{array}{llllll}9 & 12.5 & 2470 & 2-02 & 261 & 48.7\end{array}$

$\begin{array}{llllll}10 & 13.7 & 2057 & 2-26 & 249 & 46.5\end{array}$

$\begin{array}{llllll}11 & 15.0 & 1715 & 2-55 & 269 & 50.2\end{array}$

$\begin{array}{llllll}12 & 16.2 & 1471 & 3-24 & 281 & 52.5\end{array}$

$\begin{array}{llllll}13 & 17.5 & 1259 & 3-58 & 285 & 53.2\end{array}$

$\begin{array}{llllll}14 & 18.7 & 1104 & 4-32 & 308 & 57.4\end{array}$

$\begin{array}{llllll}15 & 20.0 & 965 & 5-11 & 328 & 61.2\end{array}$

$\begin{array}{llllll}16 & 21.2 & 859 & 5-49 & 357 & 66.6\end{array}$

$\begin{array}{llllll}17 & 22.5 & 748 & 6-41 & 396 & 73.9\end{array}$

$\begin{array}{llllll}18 & 23.7 & 681 & 7-20 & 422 & 78.4\end{array}$

$\begin{array}{llllll}19 & 25.0 & 618 & 8-06 & 481 & 89.8\end{array}$

$\begin{array}{llllll}20 & 26.2 & 558 & 8-58 & 517 & 96.4\end{array}$

to 5.5 hours in case of 3,000 rep irradiation, and in the range of 24 minutes to 9 hours in case of 5,000 rep irradiation. The results are diagrammed in Figure 2. As shown in the figure, in case of pure agar medium, irradiation at a dose-rate exceeding $1,700 \mathrm{rep} / \mathrm{hr}$ resulted in almost the same survival-ratios of the strain assuming the

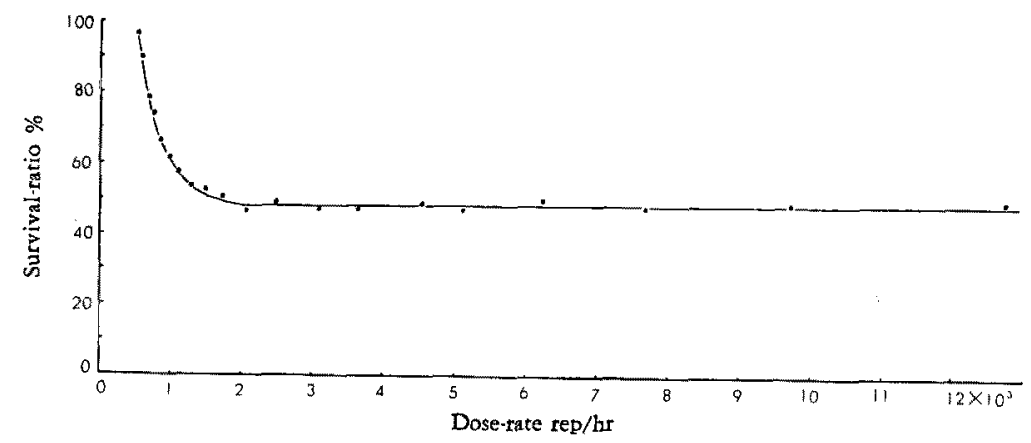

FIG. 1. Relation between Survival-ratio of $E$. coli in Minimum Medium and Dose-rate of Gamma-ray at the Dose of 5,000 rep. 


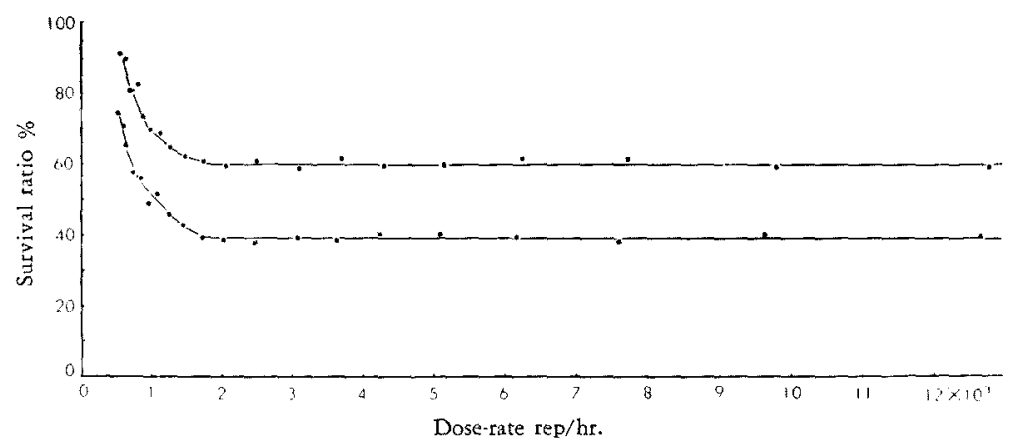

FIG. 2. Relation between Suruival-ratio of E. coli in Pure Agar Medium and Dose-rate of Gamma-ray at the Doses of 3,000 and 5,000 rep.

value of $60 \%$ in case of $3,000 \mathrm{rep}$, and $39 \%$ in case of 5,000 rep irradiation.

Finally, ten petri-dishes containing a nutrient agar medium enriched with $10 \%$ horse-serum were irradiated for varied durations in which the total doses of irradiation upon samples were almost equivalent, i. e., 15,000 rep. The durations of irradiation were adjusted in the range of 1.2 to 7.4 hours. The results are diagrammed in Figure 3. As shown in the figure, in case of a nutrient agar medium enriched with $10 \%$ horse-serum at a dose-rate of more than 4,000 $\mathrm{rep} / \mathrm{hr}$ as only in case of nutrient agar medium in Report III, the survival-ratios assumed almost the same value of $25 \%$.

As it is observed from these results, in order

TABLE II. DOSE-RATES AND DuRations OF IRRADIATION ON SAMPLES AT THE DOSE OF 15,000 REP IN CASE OF USING A NUTRIENT Agar Medium Contalnivg 10\% HorSe-SERUM

\begin{tabular}{|c|c|c|c|c|}
\hline $\begin{array}{c}\text { Sample } \\
\text { No. }\end{array}$ & $\begin{array}{l}\text { Dose-rate } \\
\text { rep/hr }\end{array}$ & $\begin{array}{l}\text { Irradiation } \\
\text { Time }\end{array}$ & Survival & $\begin{array}{c}\text { Survival } \\
\text { Ratio }\end{array}$ \\
\hline - & 0 & $0 \mathrm{hr}$ & 583 & $100 \%$ \\
\hline 1 & 12.618 & $1 \mathrm{~h}-11 \mathrm{~m}$ & 204 & 35.0 \\
\hline 2 & 9.616 & $1-34$ & 201 & 34.5 \\
\hline 3 & 7.571 & $1-59$ & 194 & 33.3 \\
\hline 4 & 6.142 & $2-26$ & 203 & 34.8 \\
\hline 5 & 5.042 & $2-59$ & 198 & 34.0 \\
\hline 6 & 4.230 & $3-34$ & 200 & 34.3 \\
\hline 7 & 3.598 & $4-11$ & 210 & 36.0 \\
\hline 8 & 3.044 & $4-56$ & 220 & 37.7 \\
\hline 9 & 2.443 & $6-08$ & 238 & 40.9 \\
\hline 10 & 2.034 & $7-23$ & 257 & 44.1 \\
\hline
\end{tabular}

to compare each survival-curve obtained from each irradiated sample, $E$. coli should be irradiated with gamma-ray at a dose-rate exceeding a certain minimum limit when bacteria are suspended in various media. Further, the rich protective substance resulted in a higher doserate limit than the poor protective matter in the medium used.

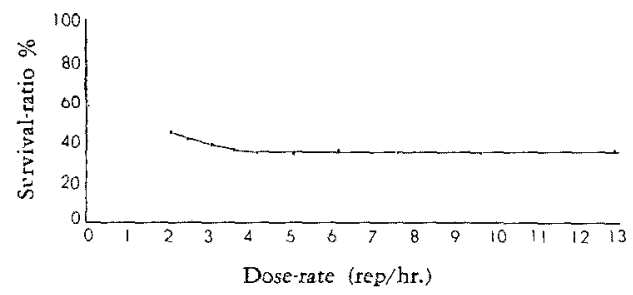

FIG. 3. Relation between Survival-ratio of $E$. coli and Dose-rate of Gramma-ray at the Dose of 15,000 rep in a Nutrient Medium containing 10\% Horse-serum.

(2) Experiment 2: In Report III, the author has reported that $E$. coli preserved at room temperature in both a nutrient agar medium and a pure agar medium prior to irradiation resulted in higher survival than those irradiated immediately after harvesting and that the longer they were preserved at room temperature, the more bacteria irradiated survived.

In this report, sample containing both $E$. coli and a medium were kept as long as 6 hours in an ice-box prior to gamma-ray irradiation. The media used were a nutrient agar medium and a pure agar medium (non-nutrient). The pre- 


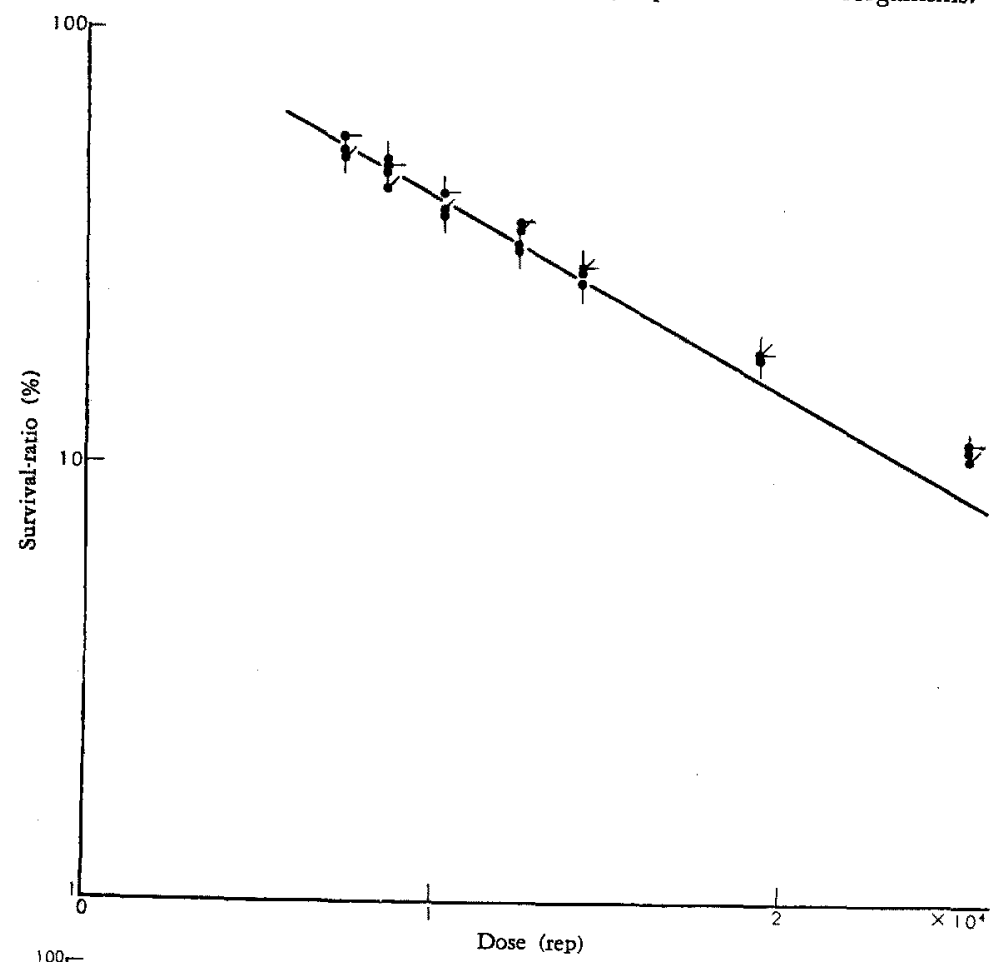

FIG. 4. Survivals of $E$. coli in Broth Agar Medium irradiated by Gamma-ray after Preserving in an Ice-box for Different Period.

- Ohr $616 \mathrm{cell} / \mathrm{ml}$

- 2577

- 4568

- 6562

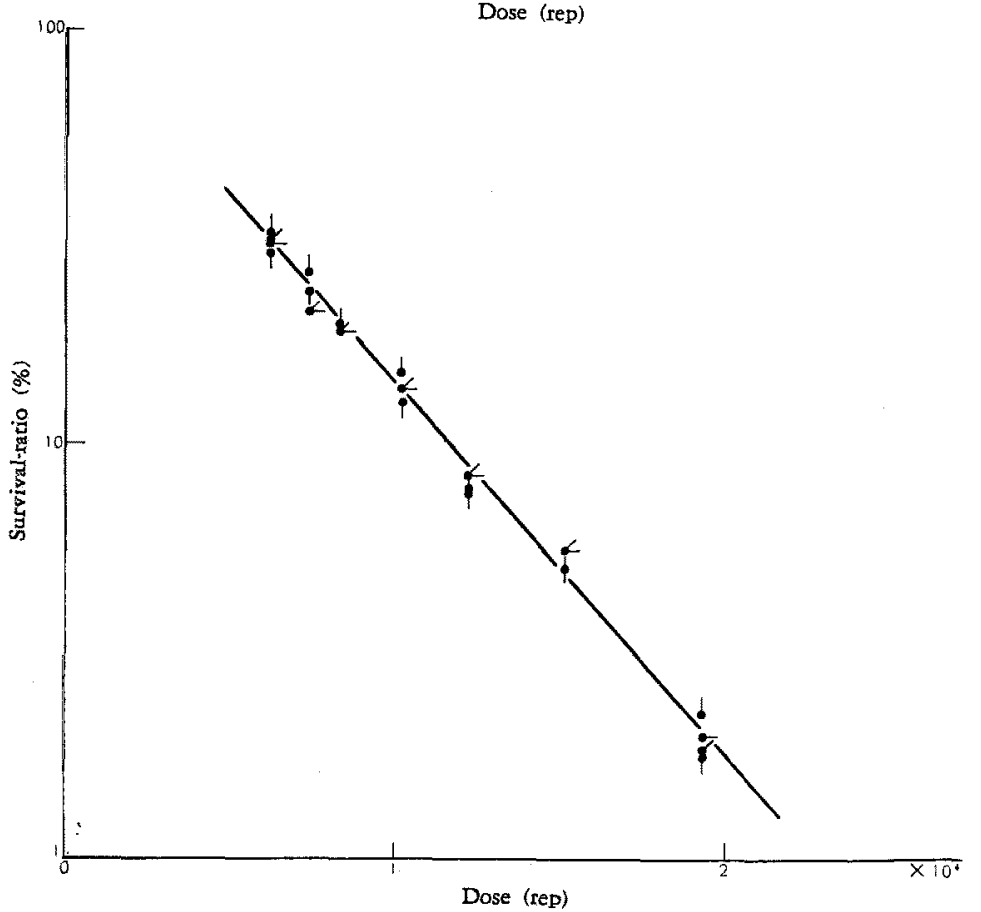

FIG. 5. Survivals of E. coli in Pure Agar Medium irradiated by Gamma-ray after Preserving in an Ice-box for Different Period.

- Ohr $418 \mathrm{cell} / \mathrm{ml}$

- 2434

- 4411

Dose (rep) 
servation periods in the ice-box were 2,4 and 6 hours respectively, the irradiation period being 2 hours in each experiment.

The results of the nutrient agar medium are diagrammed in Figure 4, Figure 5 shows the results obtained with a pure agar medium. As shown in these two figures, no influences of preservation in the ice-box for as long as 6 hours on survivals of the strain in these two media are observed. Therefore, it is supposed that the influences of the preserving procedure reported in Report III should result from biological phenomena. In case of a nutrient agar medium preserved at room temperature, the higher survivals of the strain would be due to the increase in number of viable cells. However, in case of a pure agar preserved at room temperature, the cause of higher survivals is not yet known. Consequently, the following experiment was attempted.

A highly concentrated bacterial suspension in saline was preserved in an incubator at $37^{\circ} \mathrm{C}$ prior to the preparation of samples. In this

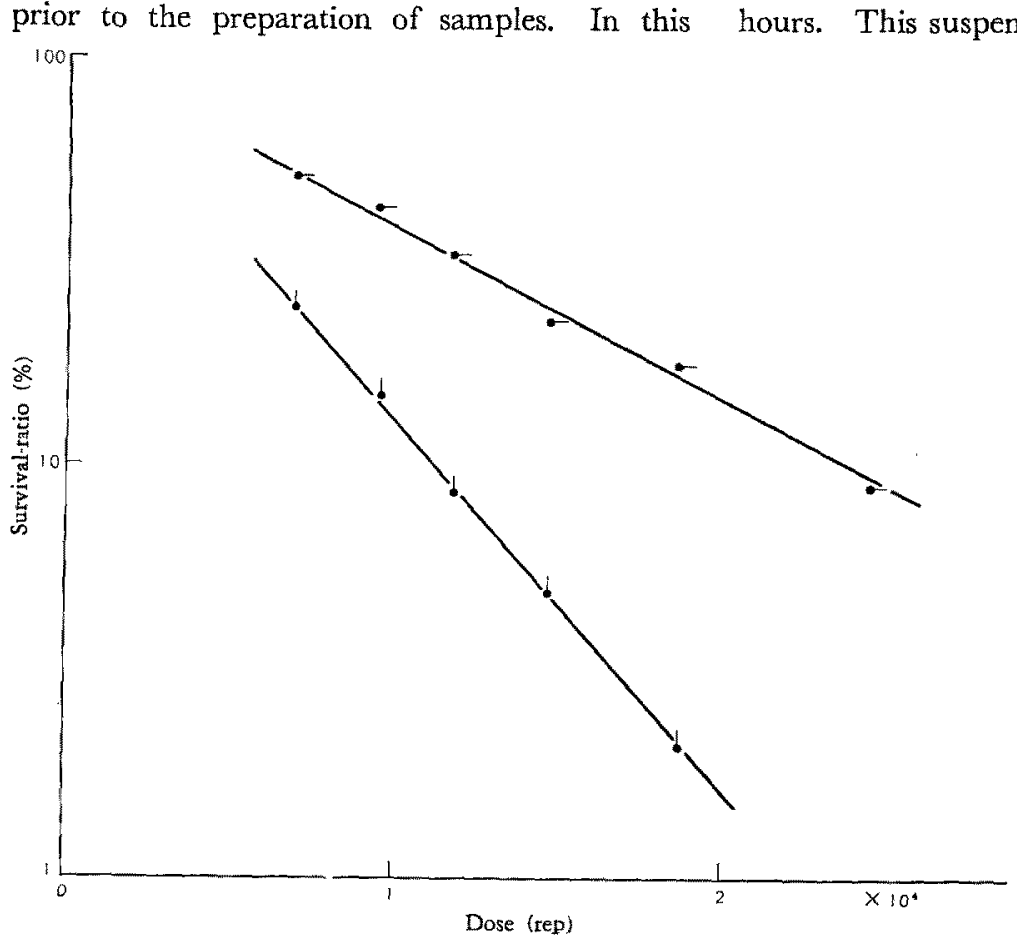

case, it was considered that the cells of the strain should become resting. The results are diagrammed in Figure 6, As it can be seen from the figure, survivals of the strain resulted higher than the control, and it was ascertained that gamma-ray resistance of the strain is increased by storage. From this results, the higher survival of $E$. coli preserved at room temperature in a non-nutrient agar may be due to the formation of resting cells resulting from preservation for such a long period.

(3) Experiment 3: In Report II, the author has reported that the addition of cells of the same strain which are cells-perished by heat have no influence on the survival-curve of E. coli.

In the present experiment, the cells of the strain of $E$. coli sterilized by gamma-ray irradiation were added to the samples. The suspension of perished cells of the strain was prepared by gamma-ray irradiation with cobalt-60 of 40 curies at a distance of $5 \mathrm{~cm}$ from the source, for 40 hours. This suspension was added to the living
Fig. 6. Influence of Preserving of Bacterial Saline at $37^{\circ} \mathrm{C}$ Prior to Addition to usedMedium upon Survival of $E$. coli irradiated with Gamma-ray.

- $0 \mathrm{hr} 418 \mathrm{cell} / \mathrm{ml}$

- 6469 


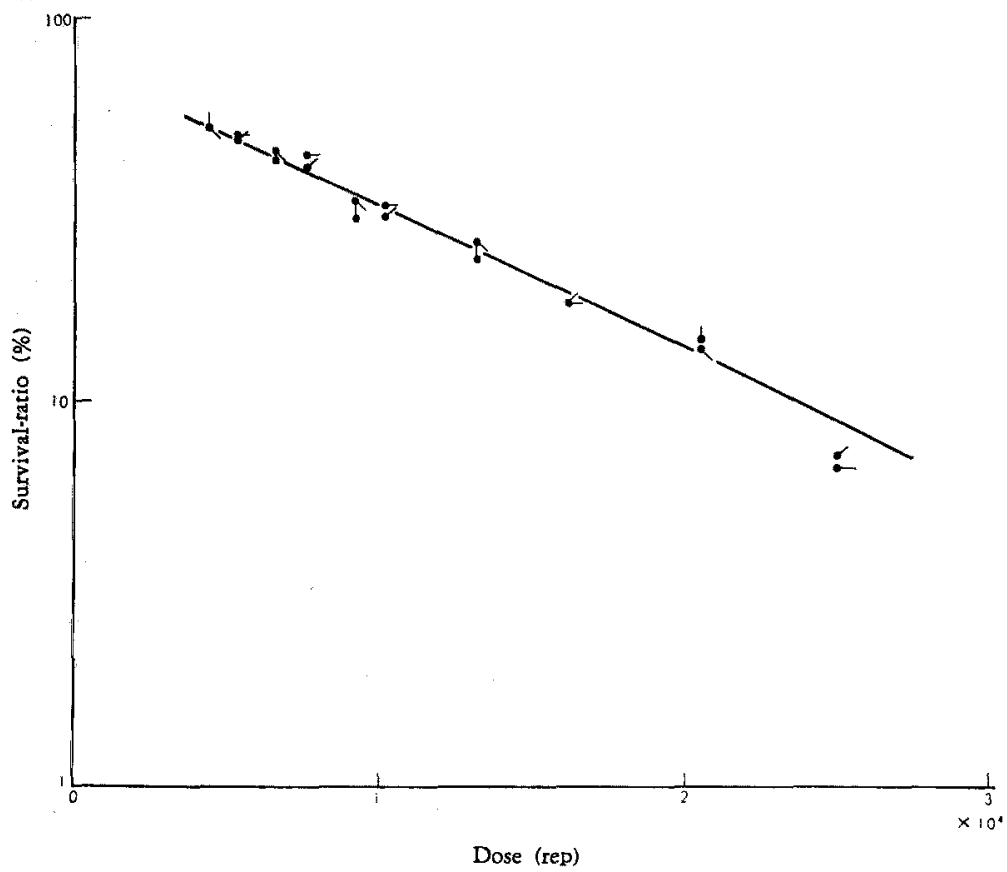

FIG. 7. Influence of Addition of Gamma-ray Sterilized Cells of E. coli upon the Same Strain by Gamma-ray Irradiation.

$\begin{array}{lll} & 0 & 695 \mathrm{cel} 1 / \mathrm{ml} \\ * 10^{7} & 674 \\ - & 10^{5} & 404 \\ & 10^{8} & 375\end{array}$

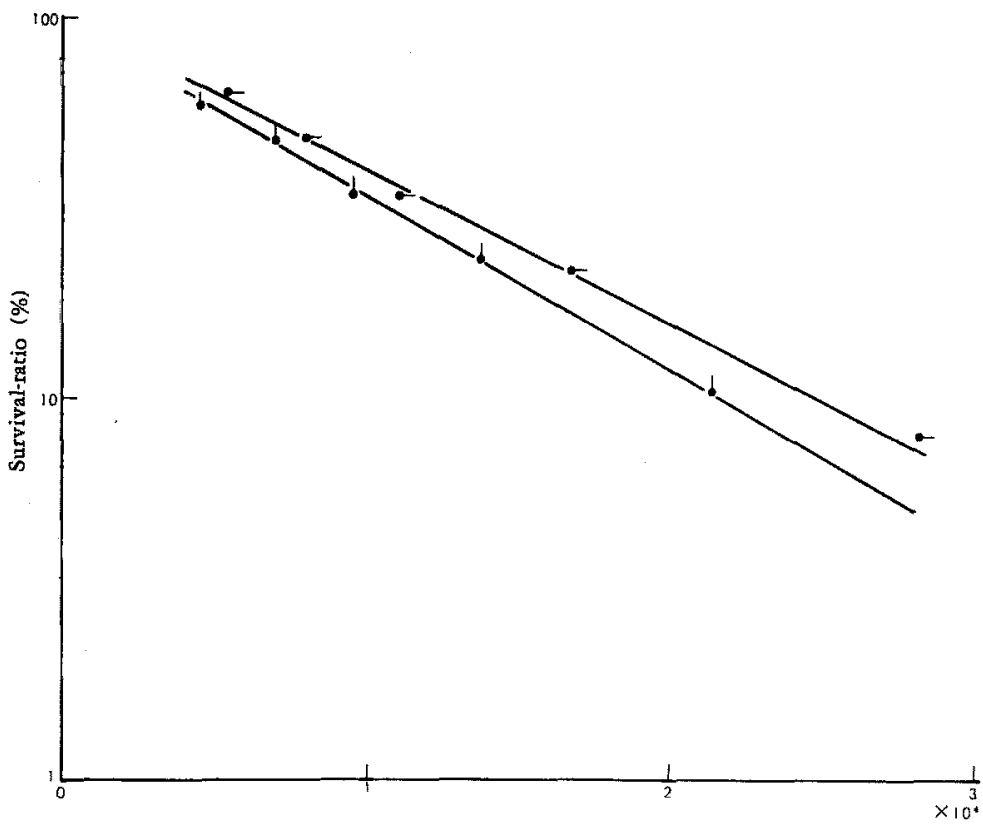

Fig. 8. Influence of Incubating Temperature after Irradiation upon Survivals of $E$. coli irradiated with Gamma-ray.

- $37^{\circ} \mathrm{C} \quad 493 \mathrm{cell} / \mathrm{ml}$

- $18^{\circ} \mathrm{C} 580$

Dose (rep) 


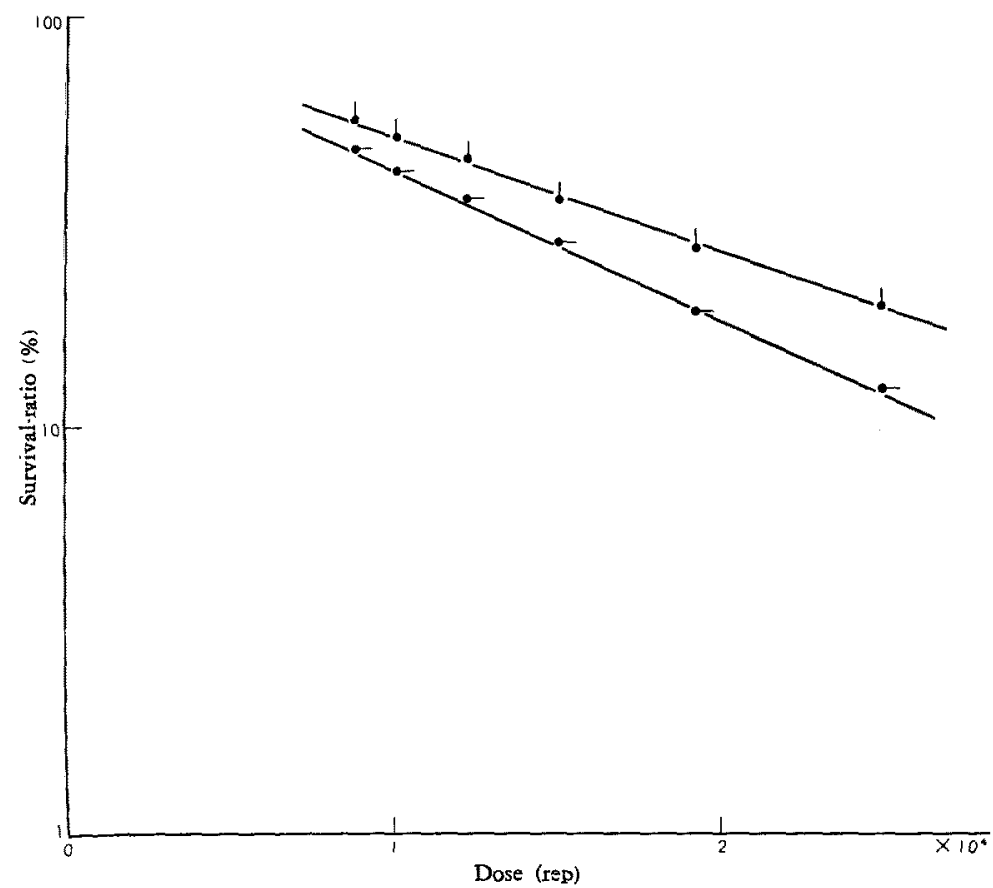

FIG. 9. Influence of Vacuum Procedure upon Survivals of $E$. coli irradiated with Gamma-ray.

- controll $683 \mathrm{cell} / \mathrm{ml}$

- 29 inch 540 vaccum

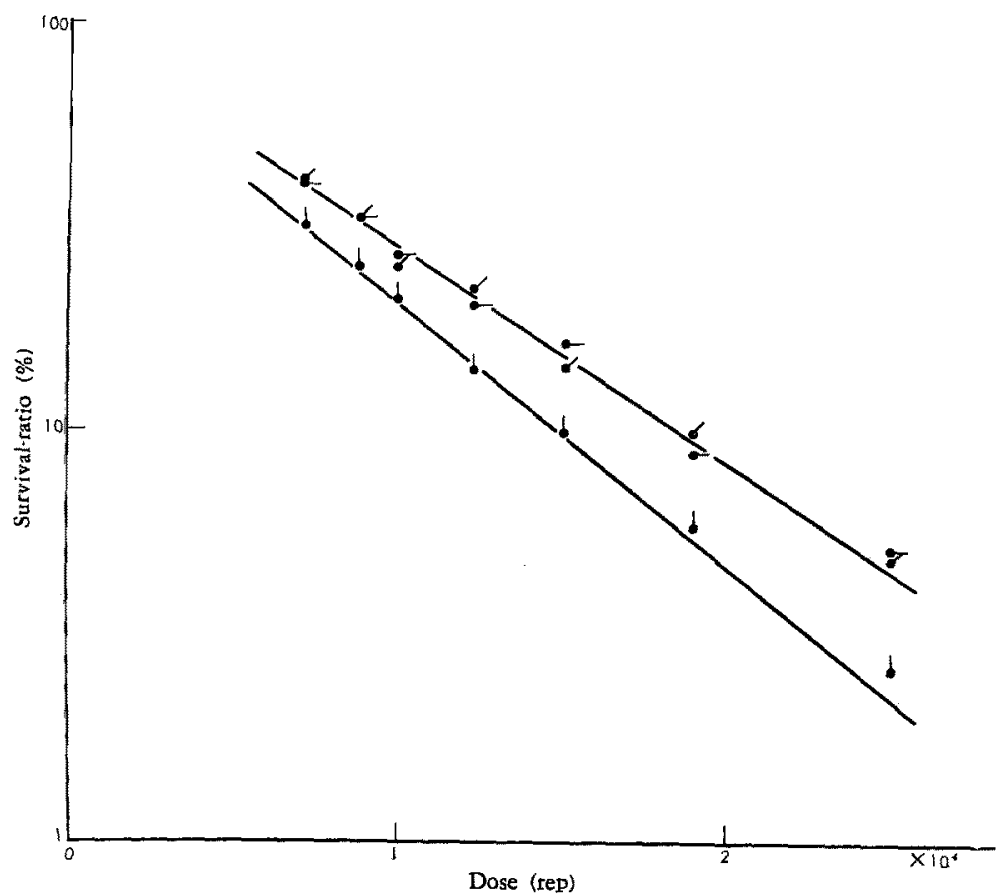

FIG. 10. Influence of Addition of Pereston- $N$ (artificial serum) upon Survivals of $E$. coli contained in a Synthetic Medium by Gamma-ray Irradiation.

- $0 \% \quad 601$ cell $/ \mathrm{ml}$

- $5 \quad 553$

- $10 \quad 569$ 
cells at concentrations of $1: 10,1: 10^{3}$ and $1: 10^{5}$ (living cell count : perished cell count).

The results are diagrammed in Figure 7. As it can be seen from the figure, no influences of the addition of perished cells of the same strain were observed on the survival-curve of $E$. coli.

(4) Experiment 4: In Report II, the author has also reported that no influences of incubation on the survival-curve of $E$. coli are observed at either $37^{\circ}$ or $25^{\circ} \mathrm{C}$.

In the present experiment, bacteria were incubated at $18^{\circ} \mathrm{G}$ after two hours irradiation until colonies developed. The results are diagrammed in Figure 8. As it can be seen from the figure, the bacteria irradiated and subsequently incubated at $18^{\circ} \mathrm{C}$ survive better than those incubated at $37^{\circ} \mathrm{C}$. Therefore, it would be considered that a part of the irradiated bacteria is recovered from irradiation damage during incubation at $18^{\circ} \mathrm{C}$.

(5) Experiment 5: In all previous reports, the bacteria were irradiated with gamma-ray in open air. As Goldblith has reported that microorganisms irradiated in vacuum are extremely resistant to gamma-ray ${ }^{5)}$, in the present experiment, all samples were packed with a Kureharon film, one of the polyvinylidene-chloride films, under a vacuum value of 29 -inch. After irradiation, samples were taken out of the package film and placed into an incubator of $37^{\circ} \mathrm{C}$. Therefore, although these samples were irradiated in vacuum, they were incubated in the air.

The results are diagrammed in Figure 9. As seen from the figure, the bacteria irradiated in vacuum survived better than those irradiated in the air. However, the protective effect of the vacuum procedure was not so remarkable as compared with the effects of other protective conditions.

(6) Experiment 6: In Report IV, the author has reported on the protective effects of the addition of horse-serum on the medium employed.

5) S.A. Goldblith, B.E. Proctor, S. Davison and E.M. Oberle, How Processing Conditions Affect Microorganisms Radioresistance, Nucleonics, 13, 42-45 (1955).
In the present experiment, the effect of "artificial-serum" upon the survival of $E$. coli was investigated. This artificial serum was Pereston-N, which contained $6 \%$ of polyvinylpyrrolidon (Bayer Corp.).

The used concentrations of the artificial serum in a pure agar medium were $5 \%$ and $10 \%$. Figure 10 demonstrates the results from which some protective effects on the survival of the strain are recognized as a result of the addition of the artificial serum to the medium. However, as it can be seen in the figure, the survival-curve obtained from the $10 \%$ artificial serum was almost similar to that $5 \%$. Therefore, when an amount of this substance exceeding a certain limit is added, any additive effect upon survival of the strain is not likely to be expected.

\section{SUMMARY}

(I) The survival-ratios of E. coli irradiated with an equal gamma-ray total dose were almost constant at a dose-rate exceeding a certain limit. This limit differed from each another. In case of nutrient medium containing $10 \%$ horse-serum, the limit was $4,000 \mathrm{rep} / \mathrm{hr}$, in case of minimum medium 2,000 rep/hr, and in non-nutrient medium $1,700 \mathrm{rep} / \mathrm{hr}$.

(2) Also, in case of applying the gamma-ray dose-rate below a certain limit, the lower the dose-rate, the more bacteria survived.

(3) When E. coli was preserved in an icebox as long as 6 hours in a nutrient agar or on a pure agar prior to irradiation, no change was observed on the survival of the strain irradiated in either case.

(4) When $E$. coli suspended in saline was preserved in an incubator for 6 hours prior to preparation of the samples, survival of the strain was higher than that of the control. The higher survival is probably due to the formation of resting cells of the bacteria.

(5) When perished cells sterilized with gamma-ray were added to the living cells of the same strain of $E$. coli, no influences on the survival-curve of the living cells were observed.

(6) The survivals of E. coli irradiated and 
incubated at $18^{\circ} \mathrm{C}$ were slightly higher than survivals of $E$. coli incubated at $37^{\circ} \mathrm{C}$. Some reactivation occurred in incubation of the irradiated bacteria at $18^{\circ} \mathrm{C}$.

(7) The survivals obtained from samples irradiated in vacuum were higher than those irradiated in the air.

(8) The protective effects of Pereston-N, which is regarded as an artificial serum, were recognized when $E$. coli was irradiated with gamma-ray.

Acknowledgement The author wishes to express his cordial thanks to Prof. T. Asai, Dept. of Agricultural Chemistry, Univ. of Tokyo, and
Prof. T. Obara, Dept. of Agr. Chem., Tokyo Univ. of Education, for their invaluable advice and constant guidance. He is also indebted to Prof. D. Ushiba, Asist. Prof. S. Sasaki, Dept. of Bacteriology, Keio Univ., for their kind suggestions, and to Prof. H. Kadota, the Research Institute for Food Science, Kyoto University, for his helpful and valuable advice. Thanks also due to Dr. H. Yamashita, Radium Center of Cancer Institute, for his sound advice concerning radio-isotopes.

This study was supported in part by a Grant'in-aid for Scientific Research defrayed from the Rockefeller Foundation.

[Bull. Agr. Chem. Soc. Japan, Vol. 24, No. 1, p. 92 95, 1960]

\title{
Studies on the Reduction of Terpenes with Sodium in Aqueous-ammonia
}

\author{
Part IV. On the Reduction of (+)-Pulegone* \\ By Hiroo Ueda and Sumio Shimizu** \\ Kesearch Institule, Nagaoka \& Co., Lld., Moloyama, Kobe \\ Received May, 14, 1959
}

\begin{abstract}
In regard of the reduction of $(+)$-pulegone with sodium in aqueous-ammonia, application of infra-red analyses and chemical methods revealed the product to be composed of $75 \%(-)$-menthol and $25 \%(+)$-isomenthol.
\end{abstract}

The reduction of pulegone has been studied by numerous investigators. On catalytic hydrogenation $^{1,2)}$ at the ordinary temperature, $(t)$ isomenthone and a small amount of $(-)$-menthone were obtained. When aluminum- or sodium-amalgam ${ }^{3)}$ was employed, pinacone was

* For Part III sec This Bulletin, 23,524 (1959).

** Laboratory of Agticultural Chemistry, Faculty of Agriculture, Shinshu University.

1) G. Vavon, Compt. rend, 155. 287 (1912).

2) A. Skita, Ber, 55, 140 (1922).

3) C. D. Harries and G. Roeder, Ber., 32, 3367 (1899). formed. By the used of aluminum-isopropoxide ${ }^{4,5)}$ the reduction was accompanied by dehydration and $p$-menthadiene was prepared, while pulegol was obtained by lithium-aluminum-hydride ${ }^{(6)}$. When pulegone was reduced with sodium and alcohol ${ }^{7,8,9)},(-)$-menthol and some pulegol were

4) W. J. Grubb and J. Read, J. Chem. Sor, 1934, 242.

5) A.G. Short and J. Read, J. Cben. Soc., 1939. 1306.

6) A.K. Macbeth and J.S. Shannon, J. Chen. Soc., 1952. 4748.

7) E. Beckmann and M. Pleissuer, Ann., 262, 30 (1891).

8) F. Tiemann and R. Schmidt, Ber., 29, 914 (1896).

9) V. Paoliai, Atti R. Accad. Lincei, 28, 190, 236 (1919). 